\title{
MUSEUM BIOTA LAUT SUNDA KELAPA
}

\author{
Alfin Aditya ${ }^{1)}$, Rudy Surya ${ }^{2)}$ \\ 1)Program Studi S1 Arsitektur, Fakultas Teknik, Universitas Tarumanagara, alfinsaik@gmail.com \\ 2) Program Studi S1 Arsitektur, Fakultas Teknik, Universitas Tarumanagara, rudys@ft.untar.ac.id
}

Masuk: 04-07-2021, revisi: 30-07-2021, diterima untuk diterbitkan: 23-10-2021

\begin{abstract}
Abstrak
Kemajuan teknologi yang sangat pesat pada zaman sekarang ini, membuat ekosistem kehidupan di bumi menjadi terganggu. Bukan hanya di darat saja terjadi kerusakan ekosistem di laut pun terutama yang disebabkan oleh ulah manusis yang menjadikan laut sebagai tempat pembuangan kotoran baik berupa sampah maupun industri. Salah satu cara mengatasi ekosistem biota laut yang disebabkan oleh kurangnya kesadaran masyarakat terhadap kehidupan biota di laut adalah melalui edukasi yang digabungkan dengan wisata atau rekreasi tepi laut. Isu melampaui ekologi menuju arsitektur untuk kebaikan dan kehidupan sebagai tema soal Stupa 8, memberikan pemikiran bagaimana arsitektur dapat ikut berperan dalam menjaga ekosistem kehidupan di laut. Dalam menjawab peran arsitektur dapat dalam kehidupan di masyarakat, berdasarkan isu dilakukan pendekatan yang menggunakan metode perancangan kontekstual. Metode ini digunakan agar terjadi konteks dari kehidupan biota laut terhadap lingkungan Sunda Kelapa yang menjadi lokasi tapak. Kontekstual yang dijadikan metode perancangan dengan memperhatikan kegiatan yang sudah ada serta sejarah keberadaan Pelabuhan Sunda Kelapa serta pernah adanya aquarium pertama di Jakarta. Kehadiran museum biota laut di area Pelabuhan Sunda Kelapa ini, akan melengkapi keberadaan museum bahari, pasar hexagonal sebagai sarana wisata dan rekreasi masyarakat di kawasan kota tua. Dengan memanfaatkan teknologi multi mediadalam peragaan materi museum serta adanya aquarium diharapkan dapat menjadi daya tarik masyarakat untuk ingin berkunjung ke museum. Dan terutama dapat berperan mengedukasi masyarakat agar lebih peduli terhadap kehidupan laut yang semakin tercemar.
\end{abstract}

Kata kunci: Ekosistem; Biota Laut; Kontekstual; Museum; Teknologi

\begin{abstract}
As a result of very rapid technological advances in this day and age, the ecosystem of life on earth is disrupted. Not only on land, there is damage to ecosystems in the sea, especiallythose caused by human activities that make the sea a place for waste disposal, both in the formof garbage and industry. The disruption of the ecosystem causes the life of marine biota to be preserved and educated to the public. One way to overcome the marine biota ecosystem causedby the lack of public awareness of the life of the marine biota is through education combined with tourism or seaside recreation. The issue of going beyond ecology to architecture for goodness and life as the theme of Stupa 8, provides ideas on how architecture can play a rolein helping to maintain the ecosystem of life in the sea. As an effort to answer how architecture can play a role in community life, from the issuesraised, an approach is used using contextual design methods. This method is used so that thereis a context of marine life in the Sunda Kelapa environment which is the location of the site. Contextual is used as a design method by taking into account existing activities and the historyof the existence of the Sunda Kelapa port and the existence of the first aquarium in Jakarta. With the presence of a marine biota museum that will be designed in the Sunda Kelapa Harbor area, it will complement the existence of a maritime museum, a hexagonal market as ameans of tourism and community recreation. By utilizing multi-media technology in demonstrating museum materials and the existence of an aquarium, it is hoped that it can attract people to want to visit the museum. And especially can play a role in educating the public to be more concerned about marine life that is increasingly polluted.
\end{abstract}

Keywords: Technology Advancement; Beyond Ecology; History and Culture; Plastic waste Pollution 


\section{PENDAHULUAN}

\section{Latar Belakang}

Pelabuhan Sunda Kelapa sudah ada sejak abad ke - 12. Pada masa itu merupakan pelabuhan terpenting kerajaan Pajajaran. Menurut penulis Portugis Tomé Pires, Kalapa adalah pelabuhan terbesar di Jawa Barat, selain Sunda (Banten), Pontang, Cigede, Tamgara dan Cimanuk yang juga dimiliki Pajajaran. Sunda Kelapa yang dalam teks ini disebut Kalapa dianggap pelabuhan yang terpenting karena dapat ditempuh dari ibu kota kerajaan yang disebut dengan nama Dayo (dalam bahasa Sunda modern: dayeuh yang berarti kota) dalam tempo dua hari. Pelabuhan ini telah dipakai sejak zaman Tarumanagara dan diperkirakan sudah ada sejak abad ke-5 dan saat itu disebut Sundapura. Pada abad ke-12, pelabuhan ini dikenal sebagai pelabuhan lada yang sibuk milik Kerajaan Sunda, yang memiliki ibu kota di Pakuan Pajajaran atau Pajajaran yang saat ini menjadi Kota Bogor. Kapal-kapal asing yang berasal dari Tiongkok, Jepang, India Selatan, dan Timur Tengah sudah berlabuh di pelabuhan ini membawa barang-barang seperti porselen, kopi, sutra, kain, wangi-wangian, kuda, anggur, dan zat warna untuk ditukar dengan rempah-rempah yang menjadi komoditas dagang saat itu.

Kekuasaan Demak di Jayakarta tidak berlangsung lama. Pada akhir abad ke-16, bangsa Belanda mulai menjelajahi dunia dan mencari jalan ke timur. Mereka menugaskan Cornelis de Houtman untuk berlayar ke daerah yang sekarang disebut Indonesia. Eskspedisinya walaupun biayanya tinggi dianggap berhasil dan Vereenigde Oostindische Compagnie (VOC) didirikan. Dalam mencari rempah-rempah di Asia Tenggara, mereka memerlukan basis pula. Maka dalam perkembangan selanjutnya pada tanggal 30 Mei 1619, Jayakarta direbut Belanda di bawah pimpinan Jan Pieterszoon Coen yang sekaligus memusnahkannya. Di atas puing-puing Jayakarta didirikan sebuah kota baru. J.P. Coen pada awalnya ingin menamai kota ini Nieuw Hoorn (Hoorn Baru), sesuai kota asalnya Hoorn di Belanda, tetapi akhirnya dipilih nama Batavia. Nama ini adalah nama sebuah suku Keltik yang pernah tinggal di wilayah negeri Belanda dewasa ini pada zaman Romawi.

Menurut catatan sejarah, pelabuhan Sunda Kelapa pada masa awal ini dibangun dengan kanal sepanjang 810 meter. Pada tahun 1817, pemerintah Belanda memperbesarnya menjadi 1.825 meter. Setelah zaman kemerdekaan, dilakukan rehabilitasi sehingga pelabuhan ini memiliki kanal sepanjang 3.250 meter yang dapat menampung 70 perahu layar dengan sistem susun sirih. Pada saat ini Pelabuhan Sunda Kelapa direncanakan menjadi kawasan wisata karena nilai sejarahnya yang tinggi. Saat ini Pelabuhan Sunda Kelapa adalah salah satu pelabuhan yang dikelola oleh PT Pelindo II yang tidak disertifikasi International Ship and Port Security karena sifat pelayanan jasanya hanya untuk kapal antar pulau.,Saat ini pelabuhan Sunda Kelapa memiliki luas daratan 760 hektare serta luas perairan kolam 16.470 hektare, terdiri atas dua pelabuhan utama dan pelabuhan Kalibaru. Pelabuhan utama memiliki panjang area 3.250 meter dan luas kolam lebih kurang 1.200 meter yang mampu menampung 70 perahu layar motor. Pelabuhan Kalibaru panjangnya 750 meter lebih dengan luas daratan 343.399 meter persegi, luas kolam 42.128,74 meter persegi, dan mampu menampung sekitar 65 kapal antar pulau dan memiliki lapangan penumpukan barang seluas 31.131 meter persegi.

Dari segi ekonomi, pelabuhan ini sangat strategis karena berdekatan dengan pusat-pusat perdagangan di Jakarta seperti Glodok, Pasar Pagi, Mangga Dua, dan lainnya. Sebagai pelabuhan antar pulau Sunda Kelapa ramai dikunjungi kapal-kapal berukuran 175 BRT. Barang-barang yang diangkut di pelabuhan ini selain barang kelontong adalah sembako serta tekstil. Untuk pembangunan di luar pulau Jawa, dari Sunda Kelapa juga diangkut bahan bangunan seperti besi beton dan lain-lain. Pelabuhan ini juga merupakan tujuan pembongkaran bahan bangunan dari luar Jawa seperti kayu gergajian, rotan, kaoliang, kopra, dan lain sebagainya. Bongkar muat barang di pelabuhan ini masih menggunakan cara tradisional. Di pelabuhan ini juga tersedia 
fasilitas gudang penimbunan, baik gudang biasa maupun gudang api. Dari segi sejarah, pelabuhan ini pun merupakan salah satu tujuan wisata bagi DKI. Tidak jauh dari pelabuhan ini terdapat Museum Bahari yang menampilkan dunia kemaritiman Indonesia masa silam serta peninggalan sejarah kolonial Belanda masa lalu. Di sebelah selatan pelabuhan ini terdapat pula Galangan Kapal VOC dan gedung-gedung VOC yang telah direnovasi. Selain itu pelabuhan ini direncanakan akan menjalani reklamasi pantai untuk pembangunan terminal multifungsi Ancol Timur sebesar 500 hektare.

\section{Rumusan Permasalahan}

a. Apakah arsitektur dapat berperan dalam perancangan bangunan yangmengkolaborasikan teknologi dan sejarah serta fenomena kehidupan sehari-hari menjadi wadah museum yang dapat mengedukasi serta menarik minat masyarakat untuk berekreasi dan berwisata?

b. Apakah Museum Pelabuhan Sunda Kelapa dapat memberikan edukasi positif bagi masyarakat agar lebih peduli terhadap ekosistem kehidupan biota laut?

\section{Tujuan dan Manfaat}

a. Memberikan solusi arsitektur untuk membuat masyarakat lebih menyadari kembalibetapa pentingnya ekosistem dalam kehidupan di laut melalui edukasi dan ke museum sekaligus berekreasi wisata pantai di Pelabuhan Sunda Kelapa.

b. Memberikan edukasi tentang bahayanya sampah plastik bagi kemaritiman Jakarta dan lebih peduli terhadap sampah plastik yang merusak ekosistem biota laut.

c. Melengkapi wisata rekreasi di Pelabuhan Sunda Kelapa dengan museum biota laut sebagai Kawasan Kota Tua yang banyak dikunjungi oleh wisatawan domestik maupun mancanegara.

\section{KAJIAN LITERATUR} Beyond Ecology

Ekologi juga dapat diartikan sebagai suatu cabang ilmu yang mempelajari tentang interaksi makhluk hidup atau kelompok makhluk hidup dengan lingkungannya. Istilah ekologi seringkali dianggap sebagai istilah asing yang jarang didengar oleh masyarakat. Bahkan, kebanyakan orang menganggap ekologi sama dengan ekosistem, padahal sebenarnya berbeda. Ecology / ekologi, diperkenalkan oleh seorang ahli biologi dari Jerman yang bernama Ernst Heinrich Philipp August Haeckel atau biasa dikenal sebagai Ernst Haeckel. Secara etimologis, ekologi berasal dari bahasa Yunani yaitu oikos dan logos. Oikos memiliki arti sebagai habitat sedangkan logos berarti ilmu. Maka jika ditelusuri lebih lanjut, ekologi memiliki arti sebagai ilmu yang mempelajari tentang hubungan antara sesama organisme serta hubungan antara organisme dengan lingkungannya. Pengertiannya pun beragam, karena beberapa ahli memiliki pengertian yang berbeda-beda. Ekologi memiliki berbagai macam pengertian, perbedaan pengertian tersebut didasari oleh dasar keilmuan ahli yang mendefinisikannya.

\section{Kontekstual}

Kontekstual merupakan klasifikasi dari bidang konteks dalam arsitektur yang dapat berhubungan dengan site dari lingkungan, kondisi bangunan sekitar, masyarakat, budaya dan material didaerah setempat. Tujuanya untuk mengarahkan desain ke dalam suatu perancangan desain. Jadi, arsitektur kontekstual adalah suatu metode perancangan yang mengkaitkan bangunan baru dengan menyelaraskan nilai-nilai karakteristik terhadap lingkungan sekitar (Marlina, 2019).

Energi dan emisi ini biasanya berasal dari transportasi, penggunaan listrik, dan masih banyak lagi. Untuk menciptakan bangunan yang melampaui ekologi, maka energi dan emisi dari bangunan tersebut harus diperhatikan, bahkan dihilangkan sama sekali. 


\section{Adaptation}

Beradaptasi berarti menyesuaikan diri sesuai dengan lingkungan. Dalam hal ini, arsitektur yang beradaptasi berarti arsitektur yang mampu disesuaikan dengan tapaknya. Jika tapak berada di lokasi yang sering hujan dan badai, maka bangunan juga harus bisa bertahan dari curahan hujan dan badai dengan intensitas yang besar, tanpa mengalami kerusakan.

\section{New Technology}

Penggunaan teknologi yang terbaru, yang diintegrasikan ke dalam bangunan, menjadi salah satu poin penting dalam membangun arsitektur ekologis. Dengan teknologi yang paling baru, emisi dari penggunaan listrik dan bahan bakar bisa berkurang dengan signifikan. Penggunaan panel surya, atau turbin untuk menghasilkan listrik bisa menjadi alternatif yang untuk mendapatkan sumber listrik yang ramah lingkungan.

\section{Ekologi Kehidupan Laut}

Komposisi Biota dan Produktivitas Hayati di eustaria terdapat tiga komponen fauna yaitu fauna lautan, air tawar dan payau. Komponen fauna yang terbesar didominasi oleh fauna lautan, yaitu hewan stenohaline yang terbatas kemampuannya dalam mentolerir perubahan salinitas dan hewan eurihalin yang mempunyai kemampuan mentolerir berbagai penurunan salinitas di bawah $30 \%$. Komponen air payau terdiri dari spesies organisme yang hidup di pertengahan daerah estaria pada salinitas antara $5-30 \%$. Spesies - spesies ini tidak ditemukan hidup pada perairan laut maupun tawar.

\section{Ruang Lingkup Ekologi Laut}

Total luas wilayan lautan tropis di Indonesia 5.8 juta KM2, yang terdiri atas laut territorial sebesar 0,3 juta KM2. Laut territorial membatasi bagian terluar Indonesia dengan lebar jalur laut 12 mil. Selanjutnya, luas perairan kepulauan adalah 2,8 juta KM2. Perairan kepulauan sering disebut dengan perairan Nusantara, merupakan perairan yang berada di bagian dalam kepulauan Indonesia. Kekayaan jenis biota laut Indonesia sangat besar sekali, namun sampai saat ini penelitian laut belum banyak dilakukan jika dibandingkan dengan penelitian laut di luar negeri. Ruang lingkup ekologi laut disini terutama dibatasi pada kehidupan biota laut khususnya di seluruh perairan Nusantara atau daerah tropis. Diharapkan dengan kejelasan ruang lingkupnya maka akan turut mengajak peran masyarakat untuk lebih gemar melakukan penelitian tentang ekologi kelautan khusunya di daerah tropis.

\section{Elemen-Elemen Dalam Studi Ekologi Laut}

Menurut Park (1963) dalam Crushing (1976) terdapat empat elemen dalam studi ekologi laut, yaitu: Individu/spesies, merupakan satuan dasar dalam mempelajari ekologi, Populasi, adalah salah satu kelompok individu dari satu spesies yang hidup dalam satu tempat tertentu, Komunitas, kelompok populasi-populasi, Ekosistem, kelompok dalam komunitas-komunitas

\section{Manfaat Laut Bagi Manusia}

Manusia sangat tergantung pada organisme lain untuk memperoleh produk-produk dasar seperti makanan, obat-obatan dan bahan baku lainnya. Manusia bukan salah satu spesies laut tetapi manusia adalah satu bagian besar dari jaring-jaring makanan. Manusia mengkonsumsi dalam jumlah besar ikan laut, udang, kerang, tiram dan alga makroskopis.

\section{Theme Park}

Ditinjau dari berbagai literatur, pengertian taman hiburan tematik di teluk Jakarta dapat diartikan secara etimologis sebagai sebuah taman besar yang menampung berbagai aktifitas publik berupa taman bertema di teluk Jakarta. 
Pengertian Museum

Museum adalah lembaga yang diperuntukan bagi masyarakat umum. Museum berfungsi mengumpulkan, merawat dan menyajikan serta melestarikan warisan budaya masyarakat untuk tujuan studi, penelitian dan kesenangan atau hiburan.

\section{METODE PERANCANGAN}

Dalam merancang museum biota laut di Sunda Kelapa ini menggunakan metode perancangan kontekstual yang berisi penjelasan-penjelasan secara deskriptif mengenai langkah-langkah apa saja yang akan digunakan dalam merancang secara keseluruhan dan terintegrasi dengan lingkungan di kawasan Kota Tua yang bersejarah dengan pasar ikan. Dalam proses rancangan terdapat beberapa langkah antara lain: tujuan perancangan, strategi perancangan, juga metode perancangan yang menjadi alat pembahasan rancangan terhadap kajuan teori yang terkait. Langkah-langkah tersebut akan menjadi proses perancangan secara runtut dari awal hingga tahapan akhir. Perancangan museum yang dilengkapi dengan taman tematik di sunda kelapa dibuat dengan beberapa tujuan, secara umum perancangan Taman Tematik merupakan suatu ruang public yang dapat mewadahi ruang terbuka hijau di Sunda Kelapa serta aktifitas rekreasi. Perancangan taman tematik juga bertujuan untuk dapat lebih memahami banyak dampak dari sampah dan pengolahannya yang pendekatannya dilakukan melalui berbagai media yakni melalui taman eduteiment dan ruang pameran.

Menciptakan strategi perancangan merupakan langkah awal yang sangat penting dalam menciptakan taman tematik yang komunikatif, efektif, informatif serta menarik dan menyenangkan khususnya bagi masyarakat. Oleh karena itu terdapat beberapa hal yang harus diperhatikan dalam menciptakan strategi perancangan. Diantaranya adalah dalam pemilihan bentuk yang dipilih pada elemen-elemen dari taman tematik ditujukan agar konsep dan tema yang dipakai lebih menonjol. Taman tematik ini di buat semaksimal mungkin yaitu komunikatif, efektif, informatif serta menarik. Diharapkan taman tematik ada bukan hanya sebagai ruang luar biasa namun juga sebagai ruang publik yang dapat mewadahi berbagai aktivitas khususnya di bidang pengembangan pariwisata di Sunda Kelapa dan pemahaman masyarakat tentang dampak bahaya dari sampah. Oleh karena itu pemilihan bentuk yang paling cocok, yaitu menggunakan bentuk yang unik yang menggambarkan suasana water front city yang ramah lingkungan.

\section{DISKUSI DAN HASIL}

\section{Bangunan Penerima}

Bangunan penerima dibuat seperti bangunan Museum Bahari sehingga kesan kontekstualnya terasa oleh pengunjung.

\section{Ampitheater Dan Taman Dermaga}

Ampitheater dibuat untuk menampilkan pertunjukan tentang sejarah Pelabuhan Sunda Kelapa dan juga sejarah bangsa Indonesia dalam memperjuangkan kemerdekaan, serta terdapat juga peragaan kostum yang terbuat dari sampah. Terdapat juga taman dermaga dimana pengunjung atau masyarakat sekitar dapat menikmati jogging track yang tersedia, dan juga dapat dijadikan tempat untuk berkumpul dan saling bertukar pikiran.

\section{Wisata Dermaga Kapal Pinisi dan Festival Jajanan}

Pada masa kejayaan Pelabuhan Sunda Kelapa, banyak sekali kapal-kapal pinisi dari berbagai negara datang lalu bersandar di Pelabuhan Sunda Kelapa, dengan adanya wisata kapal pinisi ini diharapkan dapat menarik pengunjung untuk dapat merasakan sensasi berlayar menggunakan kapal pinisi. 


\section{Desain Bangunan}

\section{LOKASI TEMPAT REKREASI DI SUNDA KELAPA}

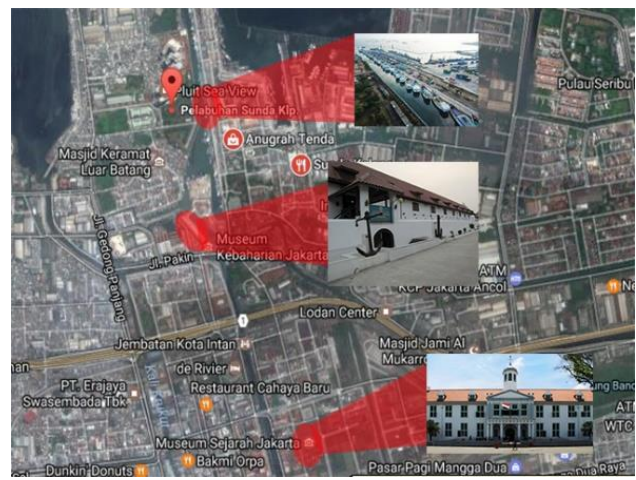

Gambar 1. Peta Tempat Rekreasi di Sunda Kelapa Sumber; Google map yang dimodifikasi penulis 2021

Hasil pengamatan di lokasi ternyata kurang sekali dengan ruang terbuka hijau, usulan proyek theme park di Sunda Kelapa sangat ideal dan memang dibutuhkan agar menambah suasana segar denagn adanya pohon-pohan serta taman yang asri, untuk memenuhi kebutuhan ruang terbuka hijau di area tersebut. Sekaligus pula juga menjadi salah satu water front city bagi masyarakat kota Jakarta khusunya di kawsaan kota tua.

\section{KARAKTERISTIK TAPAK}

Kriteria tapak :

- Berlokasi diujung tepi sungai muara pelabuhan Sunda Kelapa yang memiliki nilai sejarah bagi perkembangan kota Jakarta

- Berada satu kawasan dengan Museum Bahari yang dikenal sebagai bagian dari wisata kawasan kota tua Jakarta yang dikenal dengan Pasar Ikan Jakarta.

- Akses menuju tapak relatif mudah karena dilewati oleh berbagai jaringan transportasi umum (busway transjakarta).
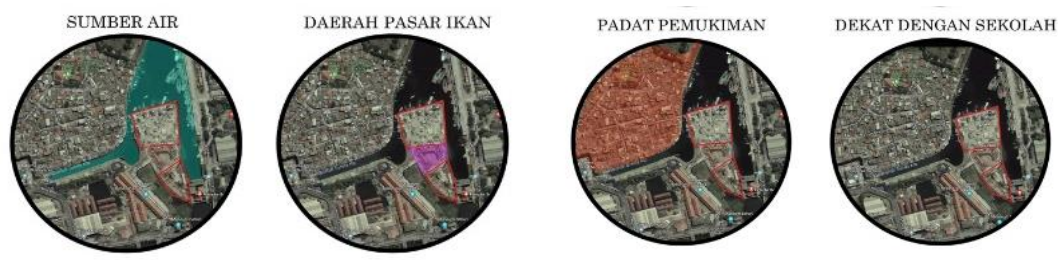

Gambar 2. Data tapak

Sumber: Google map yang dimodifikasi penulis, 2021

$\begin{array}{lll}\text { KDB } & : & 50 \\ \text { KLB } & : & 2 \\ \text { KB } & : & 4 \\ \text { KDH } & : & 30\end{array}$

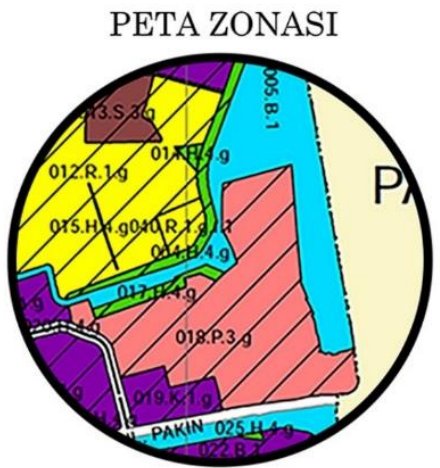

Gambar 3. peta zonasi 


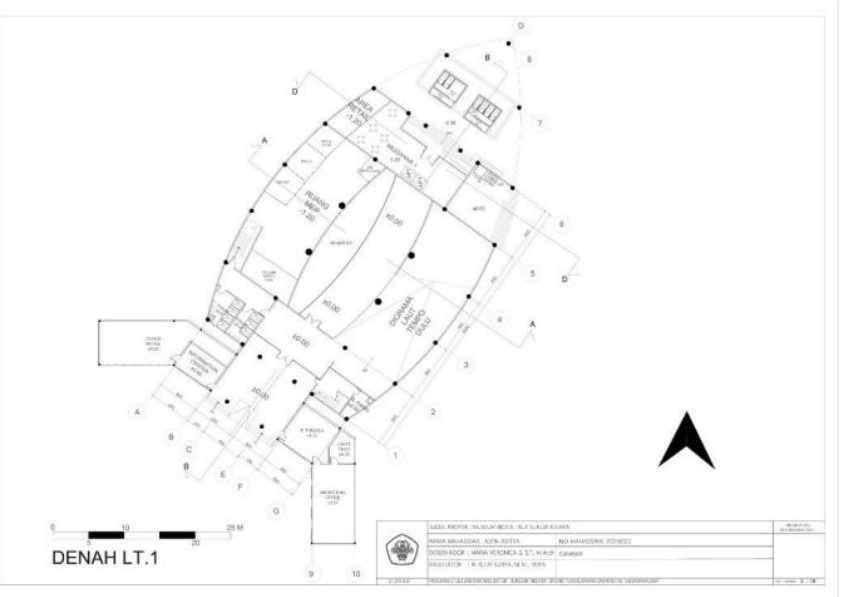

Gambar 4. Denah LT.1

Sumber: Dokumen Pribadi 2021

Pada denah It. 1, pengunjung disajikan akuarium biota laut, kemudian para pengunjung dapat menikmati diorama laut tempo dulu yang disajikan dengan tampilan modern seperti hologram dan led screen.

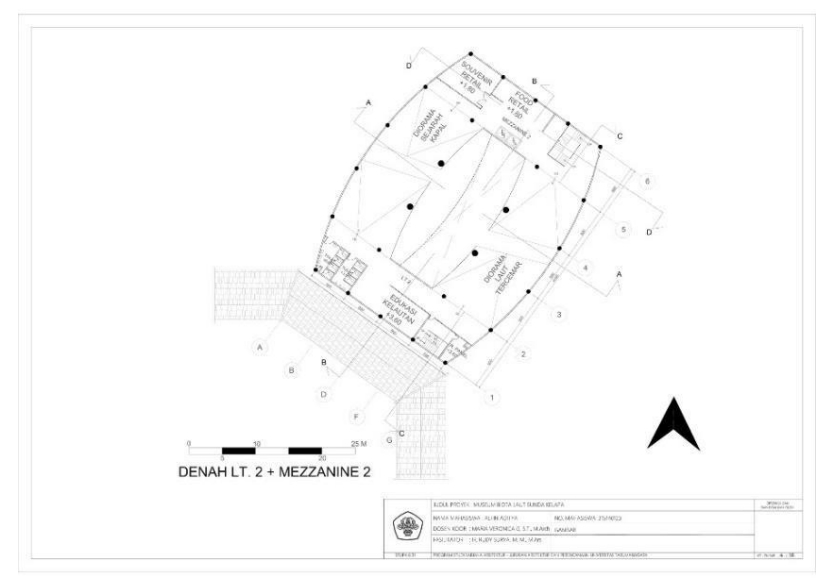

Gambar 5. Denah LT.2

Sumber: Dokumen Pribadi 2021

Pada denah It. 2, pengunjung museum dapat membeli jajanan di food retail dan souvenir, kemudian pengunjung diarahkan menuju diorama sejarah kapal pinisi. Serta pengunjung juga diberikan edukasi mengenai kelautan.

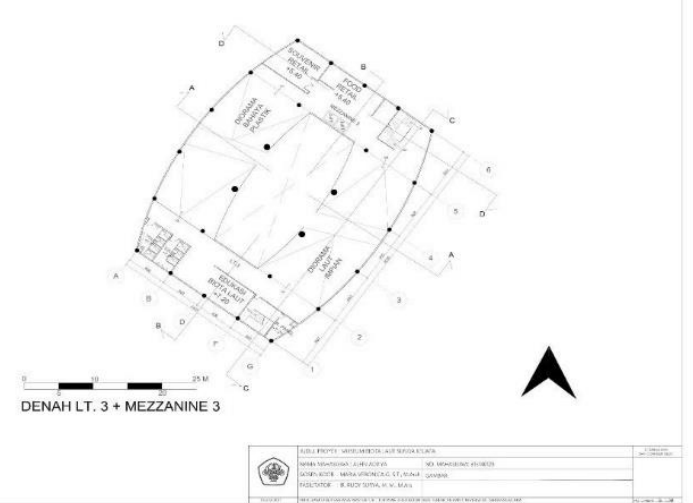

Gambar 6. Denah LT.3

Sumber: Dokumen Pribadi 2021 
Menuju It.3, pengunjung disajikan dengan diorama laut tercemar dan diorama bahaya sampah plastik pada lautan, kemudian di It.3 pengunjung diberikan edukasi mengenai biota laut.

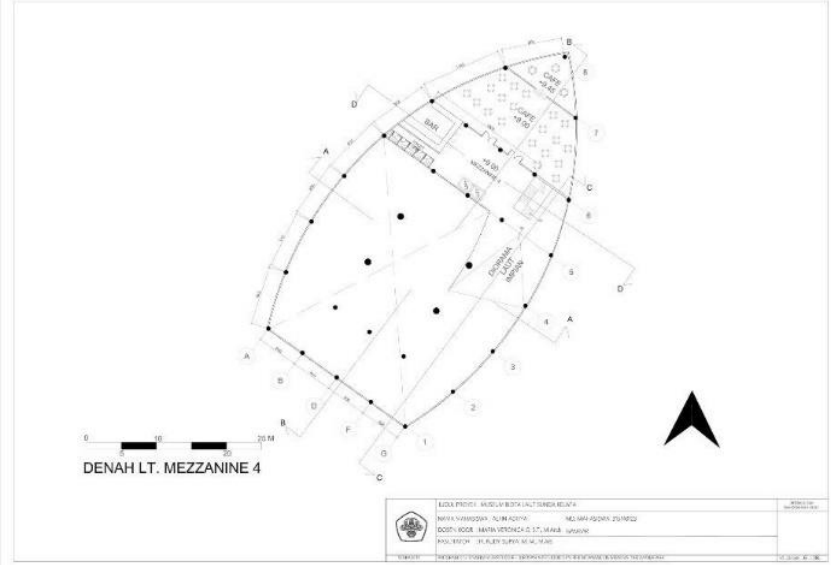

Gambar 7. Denah LT.4

Sumber: Dokumen Pribadi 2021

Menuju ke It.4, pengunjung melalui diorama laut impian, kemudian pada It.4 pengunjung dapat menikmati keindahan Pelabuhan Sunda Kelapa dari ketinggian serta menikmati hidangan café.
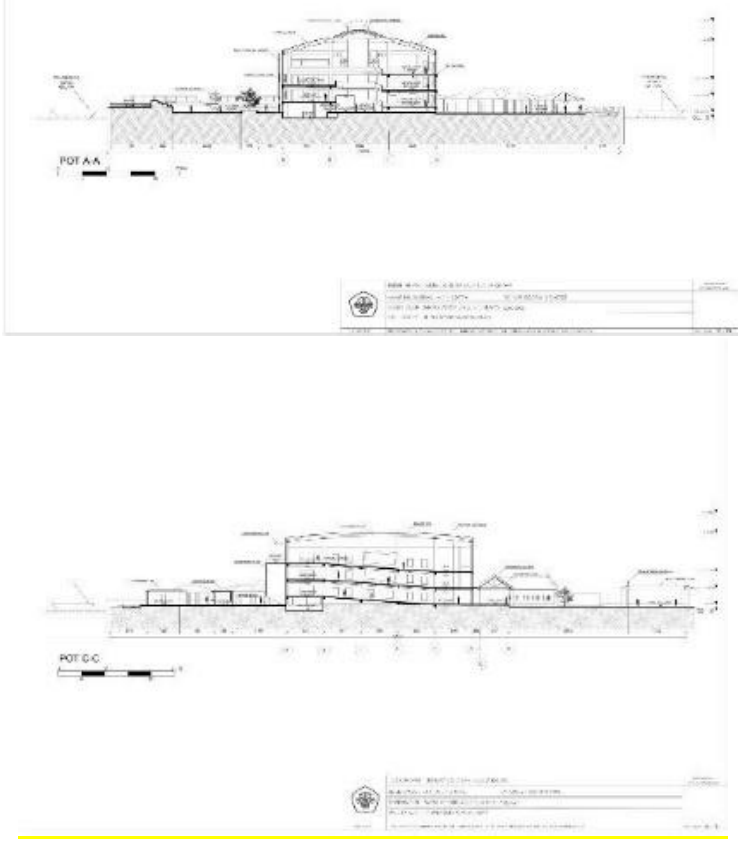

Gambar 8. Potongan

Sumber: Dokumen Pribadi 2021

Bangunan terdiri dari 4 lantai yang dimana sirkulasi pengunjung didalam museum menggunakan metode sirkulasi continue dan menggunakan ramp sebagai sarana untuk sirkulasi serta mempertunjukan dari diorama diorama yang disajikan, kemudian akses dari It. 4 menuju It. dasar menggunakan lift. 

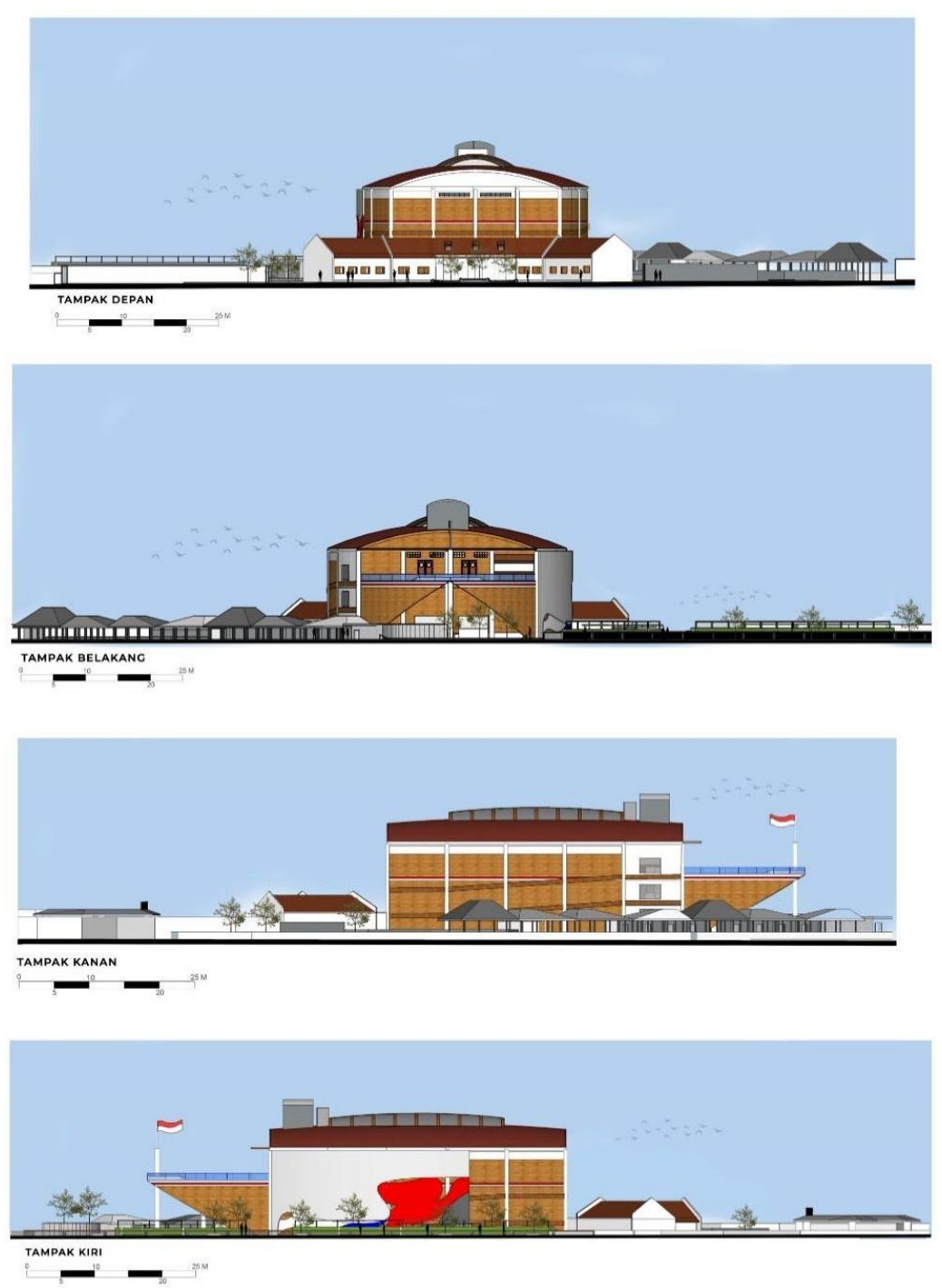

Gambar 9.Tampak

Sumber: Dokumen Pribadi 2021

Tampak pada bangunan di buat seperti kapal pinisi untuk mengenang masa kejayaan Pelabuhan Sunda Kelapa dimana pada masa jayanya Pelabuhan Sunda Kelapa sering digunakan oleh kapal pinisi dari berbagai negara untuk bersandar. Bahan yang digunakan adalah ACP dengan motif serat kayu, terdapat juga led screen pada dinding bangunan yang digunakan untuk memutar film-film dokumenter tentang sejarah bangsa Indonesia.

\section{KESIMPULAN DAN SARAN}

\section{Kesimpulan}

Perancangan proyek Museum Biota Laut Sunda Kelapa, dirancang dengan landasan untuk menghidupkan kembali kenangan sejarah Pelabuhan Sunda Kelapa mengenai Kampung Aquarium dan sejarah kapal pinisi serta menyediakan ruang terbuka bagi masyarakat untuk melakukan interaksi dengan satu sama lain. Selain itu, proyek ini diharapkan dapat meningkatkan kesadaran masyarakat Jakarta khususnya dan Indonesia umumnya akan merasakan dampak dari pencemaran ekosistem kehidupan laut. Tujuan utama dari proyek ini adalah untuk mengedukasi melalui rekreasi dan wisata bagi pengunjungnya, sekaligus menikmati keindahan muara sungai yang dulunya merupakan pelabuhan untuk kapal-kapal tradisional yang memiliki nilai sejarah. 


\section{Saran}

Studi yang dilakukan ini masih jauh dari sempurna, oleh karena itu masih harus terus dilakukan studi lanjutan agar desain bisa disempurnakan sehingga bisa diimplementasikan secara nyata di beberapa area lainnya. Desain yang dibuat juga tidak mutlak seperti demikan. Oleh karena itu dapat dihasilkan banyak alternatif bentuk dan desain lainnya yang lebih cocok dan tepat untuk diterapkan.

\section{REFERENSI}

Ching, F.D. K. (2008). Arsitektur: Bentuk, Ruang dan Tatanan. Jakarta: Penerbit Erlangga.

Fritjof, C. (1996). The Web of Life: A New Scientific Understanding of Living Systems. New York: Anchor Books.

Fachrimuhammadabror. (n.d.). Tipologi Museum. Retrieved from http://ejournal.uajy.ac.id/824/3/2TA11806.pdf

Winata, S. (2021). Eco-Logic. Universitas Tarumanagara: Jakarta

https://www.google.com/url?sa=t\&rct=j\&q=\&esrc=s\&source=web\&cd=\&ved=2ahUKEwib1eXG g-

LXAhXiX3wKHUU6CtwQFnoECBoQAA\&url=http\%3A\%2F\%2Fstaff.uny.ac.id\%2Fsites\%2Fdefault \%2Ffiles\%2FHandout\%2520Ekologi_0.pdf\&usg=AOvVaw0mkeCm0DiwXVxglg3HarJZ

https://www.google.com/url?sa=t\&rct=j\&q=\&esrc=s\&source=web\&cd=\&ved=2ahUKEwjmsoi8 hOLXAhXo63MBHRRsBC8QFnoECAQQAA\&url=http\%3A\%2F\%2Frepository.ut.ac.id\%2F430 5\%2F1\%2FBIOL4215-M1.pdf\&usg=AOvVaw1Jr8uxLeynkqF5kHCWku6W

https://www.google.com/url?sa=t\&rct=j\&q=\&esrc=s\&source=web\&cd=\&ved=2ahUKEwikvMv MhOLXAhWVj-

YKHcpzBC8QFnoECAsQAA\&url=http\%3A\%2F\%2Fdownload.garuda.ristekdikti.go.id\%2Farti cle.php\%3Farticle\%3D1005408\%26val\%3D14994\%26title\%3DPENGELOLAAN\%2520EKOSIS TEM\%2520DI\%2520WILAYAH\%2520PESISIR\%2520DAN\%2520LAUT\%2520SECARA\%2520T ERPADU\&usg=AOvVaw05KSFFuASFgDPMw34hbnqX

https://www.google.com/url?sa=t\&rct=j\&q=\&esrc=s\&source=web\&cd=\&ved=2ahUKEwjPhbkheLXAhUIIEsFHS_PANUQFnoECBMQAA\&url=http\%3A\%2F\%2Feprints.itenas.ac.id\%2F880 \%2F5\%2F05\%2520Bab\%25202\%2520212016004.pdf\&usg=AOvVaw0gs_8JDH8oWjjzY2Fw WZM-

https://www.google.com/url?sa=t\&rct=j\&q=\&esrc=s\&source=web\&cd=\&ved=2ahUKEwjB26zh heLXAhXP7HMBHWYRBsgQFnoECCOQAA\&url=http\%3A\%2F\%2Fejournal.uajy.ac.id\%2F2227\%2F3\%2F2TA12623.pdf\&usg=AOvVaw1zL6ZSsXiUD9lufIS2GnCa https://www.google.com/url?sa=t\&rct=j\& $q=\& e s r c=s \&$ source=web\&cd=\&ved=2ahUKEwjB26zh heLXAhXP7HMBHWYRBsgQFnoECBUQAA\&url=http\%3A\%2F\%2Ffuruhitho.staff.gunadarma .ac.id\%2FDownloads\%2Ffiles\%2F57625\%2FTIPOLOGI\%2BMUSEUM.pdf\&usg=AOvVaw2djy fGjiEaRII1_Wt9s-8y

https://www.google.com/url?sa=t\&rct=j\&q=\&esrc=s\&source=web\&cd=\&ved=2ahUKEwjKh_3L 5OTxAhVd_XMBHdMyBO0QFjAAegQIAxAD\&url=https\%3A\%2F\%2Fwww.academia.edu\%2 F9046736\%2FArsitektur_by_Francis_D_K_Ching_Bentuk_Ruang_dan_Tatanan_\&usg=AOv Vaw3F1B97eBvS4jSbwzTiGfzP 